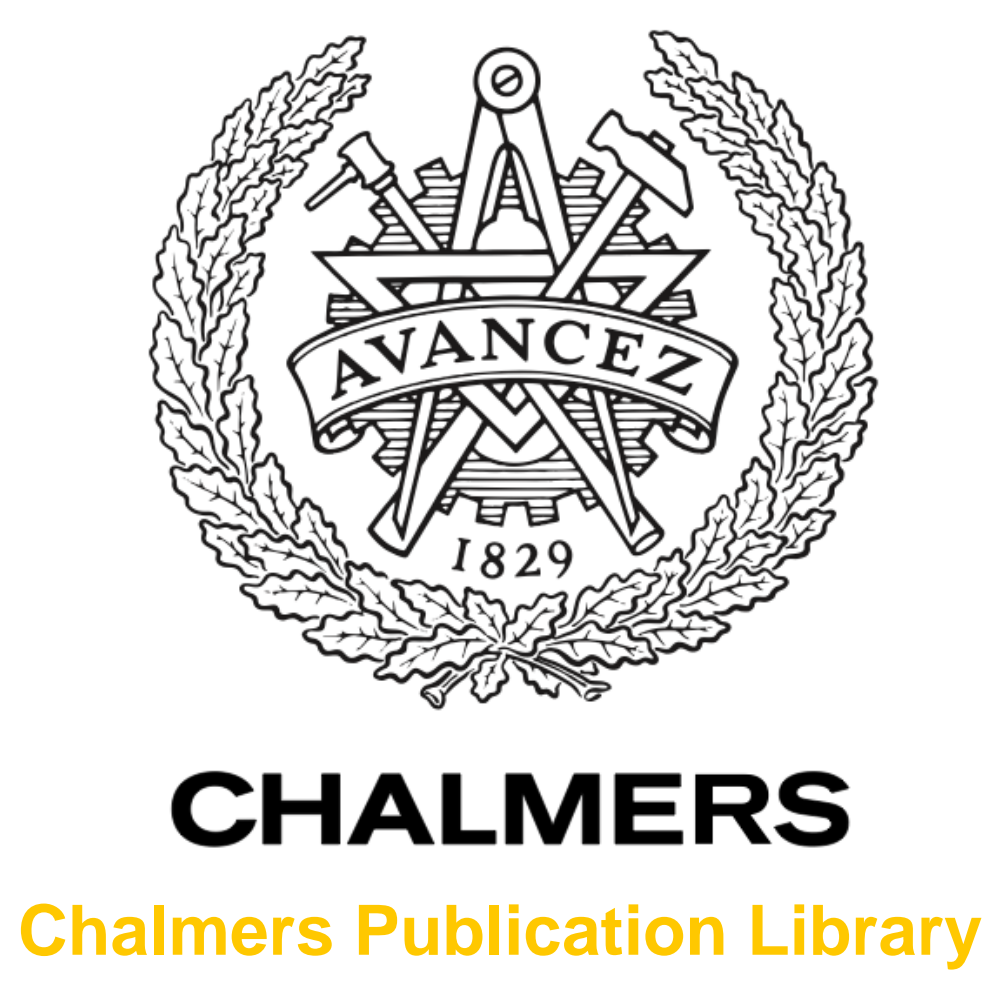

\title{
Sorption of organic pollutants frequently detected in stormwater: evaluation of five potential sorbents
}

This document has been downloaded from Chalmers Publication Library (CPL). It is the author's version of a work that was accepted for publication in:

Environmental Technology (ISSN: 0959-3330)

Citation for the published paper:

Björklund, K. ; Li, L. (2017) "Sorption of organic pollutants frequently detected in stormwater: evaluation of five potential sorbents". Environmental Technology

http://dx.doi.org/10.1080/09593330.2017.1354924

Downloaded from: http://publications.lib.chalmers.se/publication/250813

Notice: Changes introduced as a result of publishing processes such as copy-editing and formatting may not be reflected in this document. For a definitive version of this work, please refer to the published source. Please note that access to the published version might require a subscription.

Chalmers Publication Library (CPL) offers the possibility of retrieving research publications produced at Chalmers University of Technology. It covers all types of publications: articles, dissertations, licentiate theses, masters theses, conference papers, reports etc. Since 2006 it is the official tool for Chalmers official publication statistics. To ensure that Chalmers research results are disseminated as widely as possible, an Open Access Policy has been adopted.

The CPL service is administrated and maintained by Chalmers Library. 


\section{Sorption of Organic Pollutants Frequently Detected in Stormwater: Evaluation of Five Potential Sorbents}

\section{Karin Björklund ${ }^{1,2}$ and Loretta $\mathrm{Li}^{1}$}

${ }^{1}$ Department of Civil Engineering, University of British Columbia, 6250 Applied Science Lane, Vancouver, B.C. V6T 1Z4, Canada

${ }^{2}$ Department of Civil and Environmental Engineering, Chalmers University of Technology, Sven Hultins Gata 8, 41296 Göteborg, Sweden

Correspondence details: Correspondence should be addressed to Karin Björklund, email: karin.bjorklund@ chalmers.se.

Funding and grant-awarding bodies

This work was supported by the Sweden-America Foundation; the Carl Tryggers Stiftelse för Vetenskaplig Forskning under Grant CTS 12:60; and the Swedish Research Council Formas under Grant 245-2012-1607.

Acknowledgements

The authors sincerely thank Erik Bick at Rent Dagvatten for supplying the materials, and Paula Parkinson and Tim Ma for their laboratory assistance. 


\title{
Sorption of Organic Pollutants Frequently Detected in Stormwater: Evaluation of Five Potential Sorbents
}

\begin{abstract}
Adsorption filtration is one of the most promising techniques for removal of dissolved, colloidal and particulate pollutants from stormwater. The aim of this study was to compare the capacity of five filter materials - cellulose, chitosan, chitosan-covered bark, pine bark, and polypropylene/polyethylene (PP/PE) fibres - to sorb organic pollutants frequently detected in stormwater, including polycyclic aromatic hydrocarbons (PAHs), alkylphenols and phthalates. In batch tests, synthetic stormwater spiked with a mixture of the organic compounds was contacted with the materials for up to $24 \mathrm{~h}$. The compounds were then liquidliquid extracted and analyzed using GC-MS. Cellulose and chitosan showed very low sorption capacity for the organic contaminants, whereas $>70 \%$ of the initial concentration of most tested compounds was removed using PP/PE fibres, and > $80 \%$ with pine bark and chitosan-covered bark. The highest adsorption capacity was found for PAHs (up to $44 \mu \mathrm{g} / \mathrm{g}$ ) using PP/PE fibres and bark. For all tested compounds, maximum sorption was approached within 30 min using these materials. Future research using natural stormwater should investigate the effect of colloidal transport of pollutants through PP/PE fibres and pine bark and the ability of these materials to sorb other pollutants, including metals.
\end{abstract}

Keywords: adsorption filter; priority pollutants; stormwater treatment; waste materials; wood-based media 
Preprint. Accepted manuscript available online:

http://www.tandfonline.com/doi/full/10.1080/09593330.2017.1354924

\section{Introduction}

Urban stormwater is a major sink for pollutants emitted from non-point sources in the environment, including traffic-related emissions, weathering and leaching of building materials, and activities such as commerce and construction. Stormwater has been found to contain organic pollutants, including combustion by-products such as polycyclic aromatic hydrocarbons (PAH), and industrial chemicals e.g. polychlorinated biphenyls (PCB), polybrominated diphenyl ethers (PBDE), alkylphenols and phthalates, at levels that often exceed national and international environmental quality standards [1-5].

Treatment of stormwater is an important step to achieve the objectives for water quality set for example in the European Water Framework Directive. Many organic compounds detected in stormwater are hydrophobic (octanol-water partition coefficient $\log \mathrm{K}_{\mathrm{ow}}>3$, e.g. dibutyl phthalate 4.6; $\mathrm{PAH}_{16}$ 3.4-6.8; nonylphenol 4.5 [6-8]). In theory, these compounds should bind to particles and be removed, e.g. through sedimentation or filtration. However, previous studies $[3,9]$ have shown that the hydrophobic pollutants are found also in the dissolved phase in contaminated water. In addition, organic pollutants may attach to colloids such as dissolved organic carbon including humic acids in natural and contaminated waters, and hence remain dispersed in the water column [10-12]. Filters with adsorbing media have the potential to remove dissolved, colloidal and particle-bound organic contaminants and metals from stormwater. Treatment of stormwater using adsorption filters for metal removal has proven successful for a variety of low-cost media, including minerals e.g. zeolite, spinel and perlite [13-17]; coal-based materials such as anthracite and lignite [13, 14]; industrial waste products such as fly ash, blast furnace slag and chitosan $[13,18,19]$; and plantbased products e.g. pine bark, wood chips and compost $[14,15,18]$. Research on lowcost adsorbents for organic stormwater pollutants is, however, still in its infancy with 
few published reports. Boving and Neary [20] used aspen wood filters to remove PAHs in a pilot-scale stormwater field test. The average removal of PAHs over 9 weeks ranged from $19 \%$ to $36 \%$, and was correlated with molecular weight. Ray et al. [21] showed that hardwood mulch was efficient for removing dissolved naphthalene, fluoranthene and butyl benzyl phthalate (removal $\geq 77 \%$ of initial concentration, approximately 50-400 $\mu \mathrm{g} / \mathrm{L}$ ). Two minerals and three wood-based materials were previously tested as potential sorbents for PAHs, alkylphenols and phthalates [22]. The minerals vermiculite and perlite exhibited insignificant removal whereas the woodbased materials retained $\geq 80 \%$ of the initial concentration $(10-300 \mu \mathrm{g} / \mathrm{L})$ of organic compounds. These results imply that wood-based media are efficient for sorbing hydrophobic organic compounds from stormwater, likely through partition to hydrophobic sites on the media [20, 22].

The aim of the present study was to compare the adsorption capacity of five filter media - cellulose, polypropylene/polyethylene fibres, chitosan, chitosan-covered pine bark, and non-modified pine bark - for organic pollutants frequently detected in stormwater. Materials were selected based on cost and abundance, potential for reuse or recycling, water permeability and potential to sorb both hydrophobic organic compounds and metal ions. This study is part of a larger project aiming at identifying materials that have high potential use in filters for treatment of stormwater contaminated with both metals and organic pollutants. Selected materials have reported effective adsorption of metals, see e.g. [18, 19, 23].

The current study focuses on seven organic pollutants frequently detected in stormwater - three PAHs (fluorene [FL], anthracene [ANT] and pyrene [PYR]), two alkylphenols (4-nonyl- [NP] and 4-t-octylphenol [OP]) and two phthalates (dibutyl [DBP] and di(2-ethylhexyl) phthalate [DEHP]). Laboratory batch tests using synthetic 
stormwater were performed to study the adsorption kinetics and the adsorption capacities of these materials at equilibrium.

\section{Materials and Methods}

\section{Sorbents}

Five materials were selected for analysis; cellulose pellets (by-product from the pulp and paper industry), fibres made from polypropylene (PP) and polyethylene (PE) (waste product from the plastics industry), chitosan (the deacetylated form of chitin, a polysaccharide found in the exoskeletons of crustaceans, provided by BioLog, Germany), chitosan-covered pine bark (BioLog, Germany) and non-modified pine bark (Ecobark, Nyman Consulting, Sweden) (Figure 1). All media are commercially available and have, according to available information from manufacturers, previously been used for sorption of metals, oils, acids or solvents. Both barks are hydrophobic and resist wetting up to $2 \mathrm{~h}$ of soaking. The pure pine bark was sieved to the desired particle size $(0.6-2 \mathrm{~mm})$, washed and dried at $105^{\circ} \mathrm{C}$ before use. Cellulose expands considerably in water and chitosan tends to become gelatinous in certain water solutions. Therefore, chitosan flakes, chitosan-covered bark and cellulose pellets were not washed. The chitosan-covered bark was sieved (0.6-2 $\mathrm{mm})$ before use. The PP/PE is made up of up very thin fibres, up to $200 \mathrm{~mm}$ in length and susceptible to wetting. 


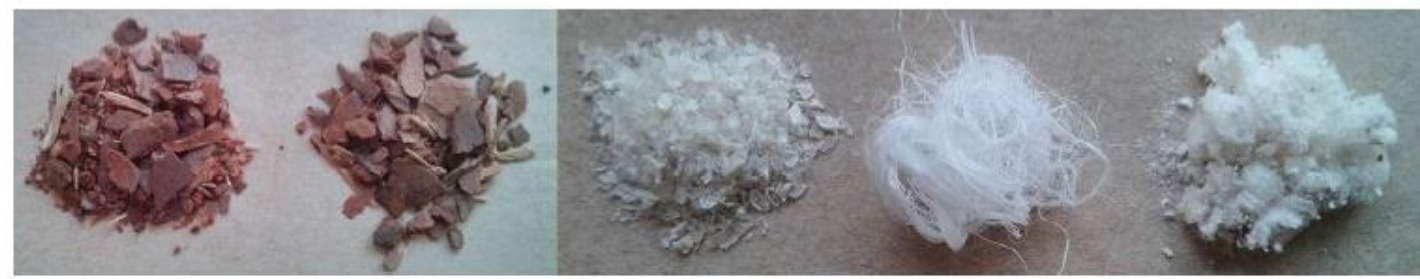

Figure 1. Materials used in the adsorption tests, shown before sieving (from left to right): non-modified pine bark, chitosan-covered pine bark, chitosan, polypropylene/polyethylene fibres, and cellulose.

The organic content of the materials was determined by percentage weight lost on ignition (LOI) at $550^{\circ} \mathrm{C}$ [24]. The conductivity (Radiometer Copenhagen CDM3 Conductivity meter) and $\mathrm{pH}\left(\right.$ Oakton $\mathrm{pH} / \mathrm{mV} /{ }^{\circ} \mathrm{C}$ meter, $\mathrm{pH} 11$ Series) were measured with demineralized water, according to Agriculture Canada approved methods (84-003 and 84-001, respectively) [24]. The specific surface area was determined by the BET nitrogen adsorption method, using a FlowSorb II 2300 surface analyzer (Micromeritics).

\section{Analytical Standards}

Standards of 4-nonlyphenol (85\% content of para-isomers), fluorene, anthracene, pyrene, dibutyl phthalate and di(2-ethylhexyl) phthalate were purchased from SigmaAldrich and 4-t-octylphenol from Fluka. Stock standard solutions of the organic compounds and internal standards - 9-chloroanthracene and phenanthrene- $\mathrm{d}_{10}$ (both from Sigma-Aldrich) - were prepared in toluene (Caledon Laboratories Ltd.) to final concentration approximately 5,000 $\mathrm{ng} / \mu \mathrm{L}$. Working standards, used to spike the water samples, were diluted in acetone (Fisher Scientific) to final concentration approximately $100 \mathrm{ng} / \mu \mathrm{L}$. 
Preprint. Accepted manuscript available online:

http://www.tandfonline.com/doi/full/10.1080/09593330.2017.1354924

\section{Leaching of Dissolved Organic Carbon and Organic Pollutants from Raw}

\section{Materials}

One gram of each material ( $0.1 \mathrm{~g}$ of the cellulose, due to its expansion in water) was mixed, using an end-over-end tumbler, with $50 \mathrm{~mL}$ ultrapure water for $24 \mathrm{~h}$ at room temperature $\left(20 \pm 2^{\circ} \mathrm{C}\right)$. The samples were filtered through $0.45 \mu \mathrm{m}$ cellulose nitrate filters (Millipore) and analyzed for leached dissolved organic carbon (DOC) using a Lachat Instrument IL 500 TOC analyzer. For analysis of leached organic compounds (FL, ANT, PYR, NP, OP, DBP and DEHP) from media, $3 \mathrm{~g}$ of each material ( $0.3 \mathrm{~g}$ cellulose) was mixed with $150 \mathrm{~mL}$ ultrapure water for $24 \mathrm{~h}$.

\section{Adsorption Tests}

Adsorption was studied through batch tests with synthetic stormwater containing dissolved organic material, here humic acids (HAs), spiked with a mixture of organic compounds. The sample composition is a simplification of natural conditions where pollutants coexist and where dissolved organic material can affect the solubility, and therefore the adsorption, of organic pollutants and metals $[25,26]$. A HA stock solution was prepared by dissolving Fluka humic acid in ultrapure water (see Björklund and Li [22] for details). The samples (150 mL ultrapure water) were spiked with the HA stock to $20 \mathrm{mg} \mathrm{DOC/L}$ final concentration, typical of what is found in natural stormwater samples [27], and the $\mathrm{pH}$ was adjusted to 7. The samples were thereafter spiked at five different concentrations $(10,50,100,200,300 \mu \mathrm{g} / \mathrm{L})$ with a mixture of all seven organic compounds (FL, ANT, PYR, NP, OP, DBP and DEHP). $1.0 \mathrm{~g}$ of each material ( $0.10 \mathrm{~g}$ of cellulose due to its expansion in water) was then added to the spiked solution and shaken, using an end-over-end rotator at room temperature $\left(20 \pm 2^{\circ} \mathrm{C}\right)$, for $24 \mathrm{~h}$. Samples were then centrifuged at $2000 \mathrm{rpm}$ for $10 \mathrm{~min}$, and those containing bark were 
also sieved through a stainless steel mesh (No. 100). The samples (150 mL HA solution, $20 \mathrm{mg}$ DOC/L, $1.0 \mathrm{~g}$ material) for adsorption kinetics tests were spiked to $100 \mu \mathrm{g} / \mathrm{L}$ with a mixture of the seven organic compounds and shaken for 10, 20, 30, 60 and 120 min before centrifugation and sieving. For each set of tests, a matrix blank and a matrix spike were prepared, following the above procedures, to determine contamination and loss of analytes, respectively. All samples were prepared in duplicate.

Adsorption of humic acids to the materials was tested by adding $1.0 \mathrm{~g}$ material to $50 \mathrm{~mL}$ HA-solution (initial concentration approximately $15 \mathrm{mg} \mathrm{DOC} / \mathrm{L}$ ). The samples were shaken with an end-over-end tumbler at room temperature $\left(20 \pm 2^{\circ} \mathrm{C}\right)$ for $24 \mathrm{~h}$, filtered through $0.45 \mu \mathrm{m}$ cellulose nitrate filters and analyzed for remaining DOC concentrations. All samples were prepared in triplicates.

\section{Sample Extraction and Analysis}

All organic compounds left in the water phase after adsorption were simultaneously liquid-liquid extracted with $3 \times 25 \mathrm{~mL}$ dichloromethane (Fisher Scientific). The extracts were evaporated using a rotary evaporator and then further concentrated under a stream of $\mathrm{N}_{2}$. The samples were reconstituted with $1.0 \mathrm{~mL}$ toluene and internal standards (9chloroanthracene and phenanthrene-d ${ }_{10}$, final concentration $100 \mu \mathrm{g} / \mathrm{L}$ ) were added before analysis using a $6890 \mathrm{HP} /$ Agilent gas chromatograph (30 $\mathrm{m} \times 0.25 \mathrm{~mm}$ I.D. DB-5 column from J\&W Scientific, Folsom, USA) with a 6890 series injector and a quadrupole 5973 mass selective detector from Agilent Technologies, Wilmington, USA. A detailed description of the GC-MS procedure, as well as all chemicals used for the extraction and analysis, was provided by Björklund and Li [22]. 


\section{Data Analysis}

The program IBM SPSS Statistics 22 was employed to perform independent samples $t$ tests.

The concentrations of organic compounds left in solution after sorption were used to calculate the percentage retention $(R, \%)$ of organic compounds, also called removal efficiency:

$R(\%)=\frac{\left(C_{0}-C_{e}\right)}{C_{0}} \times 100$

where $C_{0}$ is the initial concentration $(\mu \mathrm{g} / \mathrm{L})$ of the organic compounds in the sample solution; $C_{e}$ is residual concentration in solution at equilibrium $(\mu \mathrm{g} / \mathrm{L})$, assumed to be reached after $24 \mathrm{~h}$ contact time.

The adsorption capacity at equilibrium, $q_{\mathrm{e}}(\mu \mathrm{g} / \mathrm{g})$, was calculated using:

$q_{e}=V \times \frac{C_{0}-C_{e}}{m}$

where $C_{0}$ and $C_{e}$ are the initial and equilibrium concentrations $(\mu \mathrm{g} / \mathrm{L})$, respectively; $V$ is the volume of the solution (L) and $m$ is the weight of the adsorbent $(\mathrm{g})$.

Linearized forms of both the Freundlich and the Langmuir models were used to study the adsorption isotherms of PP/PE fibres, pine bark and chitosan-covered bark.

$$
\log q_{e}=\log K_{F}+\frac{1}{n} \log C_{e} \text { (Freundlich) }
$$




$$
\frac{1}{q_{e}}=\frac{1}{q_{\max }}+\frac{1}{K_{L} \times q_{\max }} \times \frac{1}{C_{e}} \text { (Langmuir) }
$$

where $q_{e}$ is the amount of analytes adsorbed onto adsorbent at equilibrium $(\mu \mathrm{g} / \mathrm{g}) ; C_{e}$ is the equilibrium concentration of analytes remaining in solution $(\mu \mathrm{g} / \mathrm{L}) ; K_{F}$ $\left((\mu \mathrm{g} / \mathrm{g})(\mathrm{L} / \mu \mathrm{g})^{1 / \mathrm{n}}\right), n$ and $K_{L}(\mathrm{~L} / \mu \mathrm{g})$ are adsorption-system-specific constants; and $q_{\max }$ is the maximum adsorption capacity $(\mu \mathrm{g} / \mathrm{g})$. The isotherm constants are evaluated from linear plots of the equations.

Commonly used kinetic models to evaluate the adsorption rate are the Lagergren pseudo-first-order adsorption rate equation and the pseudo-second order equation [28, 29]:

$$
\begin{gathered}
\log \left(q_{e}-q_{t}\right)=\log q_{e}-\frac{k_{1}}{2.303} t(\text { pseudo-first-order) } \\
\frac{t}{q_{t}}=\frac{1}{k_{2} q_{e}^{2}}+\frac{1}{q_{e}} t \text { (pseudo-second order) }
\end{gathered}
$$

where $q_{e}$ and $q_{t}$ are the amounts of adsorbed analytes $(\mu \mathrm{g} / \mathrm{g})$ onto adsorbent at equilibrium and at time $t(\mathrm{~min})$, respectively; $k_{l}(1 / \mathrm{min})$ is the rate constant for firstorder sorption; $k_{2}(\mathrm{~g} /(\mu \mathrm{g} \min ))$ is the rate constant of second-order sorption. The best fitting model was determined by plotting $\log \left(q_{\mathrm{e}}-q_{t}\right)$ vs $t$ and $\left(t / q_{t}\right)$ vs $t$ and comparing corresponding linear regression correlation coefficients for each compound. Based on the $t / q$ vs $t$ plot, the intercept and the slope were used to calculate the rate constant $k_{2}$ and the equilibrium adsorption $q_{e}$ for the pseudo-second-order model. 


\section{Results and Discussion}

\section{Characteristics of the Materials}

Cellulose and pine bark exhibited very low BET surface areas (Table 1). Unfortunately, BET could not be measured for chitosan and chitosan-covered bark due to instrument failure. Reported surface areas for chitosan are of the same magnitude as cellulose and bark [30]. Surface areas of high-capacity adsorbents, such as activated carbon, are typically in the 200-1200 $\mathrm{m}^{2} / \mathrm{g}$ range [31]. The comparatively low leaching of DOC from cellulose, but high conductivity, is possibly due to the presence of ionizable moieties such as carboxyl and hydroxyl groups and high ash content (13\%, Table 1). The acidic $\mathrm{pH}$ 's of the bark materials are due to leaching of humic and fulvic acids [32], and thus associated with the leaching of DOC (Table 1).

Table 1. Characteristics of sorbents.

\begin{tabular}{llllll}
\hline Materials & $\begin{array}{l}\text { BET surface } \\
\text { area }\left(\mathrm{m}^{2} / \mathrm{g}\right)\end{array}$ & $\begin{array}{l}\text { Organic } \\
\text { matter }(\%)\end{array}$ & $\mathrm{pH}$ & $\begin{array}{l}\text { Conductivity } \\
(\mu \mathrm{S} / \mathrm{cm})\end{array}$ & $\begin{array}{l}\text { Leached } \\
\text { DOC }(\mathrm{mg} / \mathrm{L})\end{array}$ \\
\hline Pine bark & 1.4 & 99 & 3.9 & 37 & 95 \\
Chitosan-covered bark & Not analyzed & 99 & 3.9 & 50 & 190 \\
Chitosan & Not analyzed & 99 & 8.0 & 72 & 11 \\
PP/PE fibre & Not detected & 91 & 9.3 & 22 & 2.0 \\
Cellulose & 1.1 & 87 & 8.1 & 131 & 20 \\
\hline
\end{tabular}

\section{Leaching of Organic Compounds from Materials}

None of the tested materials desorbed organic compounds (FL, ANT, PYR, NP, OP, DBP and DEHP) in detectable amounts. The exception was chitosan, which exhibited substantial contamination of DBP (approximately $50 \mu \mathrm{g} / \mathrm{L}$ ). Contamination with DBP was not detected in samples with chitosan-covered bark. However, background 
Preprint. Accepted manuscript available online:

http://www.tandfonline.com/doi/full/10.1080/09593330.2017.1354924

contamination $(<4 \mu \mathrm{g} / \mathrm{L})$ with the two phthalates DBP and DEHP could be detected in most samples.

\section{Adsorption and Leaching of DOC from Materials}

Only chitosan was able to adsorb humic acids (approximately $0.2 \mathrm{mg} / \mathrm{g}$ ). The aminogroup of chitosan is positively charged at $\mathrm{pH}$ 's lower than its $\mathrm{pK}_{\mathrm{a}}$, which lies between 6.3 and 6.5. The HA solution was adjusted to $\mathrm{pH}=7$ before adsorption tests began. Adding chitosan to the solution is likely to increase $\mathrm{pH}$ even more (Table 1); thus the chitosan surface was assumed to be neutral during the tests. Other studies have shown that significant amounts of HA are adsorbed onto chitosan under acidic $\mathrm{pH}$ conditions $[33,34]$ : due to attractive forces between the protonated chitosan amino-group and carboxyl or phenolic groups on the humic acid macromolecules, organic complexes may be formed. Humic acid adsorption onto chitosan is notably reduced at $\mathrm{pH}>\mathrm{pK}_{\mathrm{a}}$ $[33,34]$, as is the case in the current study. Cellulose and barks exhibit negative surface charge [35], as do humic acids at neutral $\mathrm{pH}$. Hence limited adsorption of HA occurs. Adsorption of HA onto chitosan-covered bark may occur, but is masked by the release of DOC from the bark moiety.

Pine bark and chitosan-covered bark desorbed DOC up to almost 100 and 200 $\mathrm{mg} / \mathrm{L}$ (Table 1), respectively, exceeding levels found in natural stormwater (typically 20-30 mg/L). The other materials desorbed DOC to a much lower degree (<20 mg/L). The wood-based materials may leach DOC in the form of e.g. lignin, humic and fulvic acids. Genç-Fuhrman et al. [13] considered pine bark to be unsuitable for adsorption of metals in stormwater, because of the possible transportation of metals with organic acids from the bark. Kalmykova et al. [26] showed that DOC leaching from a peat column fed with a metal solution correlated significantly with leached metal 
concentrations in the initial stage of the experiment. Leaching was partly attributed to colloidal metal-organic complexes formed with easily-soluble organic matter from the peat, e.g. humic and fulvic acids. However, in the Kalmykova et al. [26] studies, leaching of both metals and DOC decreased quickly. Therefore, DOC leaching from peat is assumed to not affect the performance of the material, e.g. when used in filters, in a longer perspective. Bark is expected to behave in a similar way to peat; after washing the bark with several batches of water, reduced leaching of DOC was observed. Hence colloidal transport of organic compounds with DOC from the material itself is expected to be limited, except during the filter start-up phase.

In another study, Kalmykova et al. [10] showed that humic colloids and thereto attached organic contaminants are not efficiently adsorbed by peat filters. Since humics contain both non-polar and polar surface groups, many organic compounds are expected to attach to humic colloids. The Kalmykova et al. studies $[10,26]$ indicate that if metals and organic pollutants are attached to humic colloids in water, the colloids may negatively affect the pollutants' adsorption onto e.g. wood-based media, which, similar to peat, exhibit the same surface charge as the humics. It is concluded that although leaching of DOC from barks is not assumed to affect the performance of the material in the long run, organic compounds attached to naturally occurring humic colloids in the water phase may exhibit limited adsorption onto bark.

\section{Removal of Organic Compounds}

\section{Cellulose and Chitosan}

Chitosan was able to adsorb the most hydrophobic PAH, i.e. pyrene, and nonylphenol, but none of the other compounds tested (Figure 2). Low removal was expected for all compounds, due to the material's low hydrophobicity. However, another study found 
that PAHs may indeed adsorb to chitosan; higher molecular weight, hence higher hydrophobicity, of the compound generally results in more favourable adsorption onto chitosan [36]. In addition, Lang et al. [37] found that nonylphenol may adsorb to chitosan through non-polar van der Waals forces. Contamination of DBP from the material disguised any adsorption that might have taken place.

The efficiency of cellulose in removing the organic contaminants was very low (Figure 2). In fact, there was no significant difference in retention of compounds in contact with cellulose (mean $[M]=76$, standard deviation $[S D]=16$ ) and compound losses during extraction and analysis $(M=82, S D=18), t(14)=0.69, p=.500$ (independent samples $t$-test). The low adsorption capacity of cellulose for organic contaminants was expected due to its polarity and negative surface charge, which promote sorption of cations [35]. Cellulose may undergo chemical modification, for example through chemical grafting, to enhance the adsorptivity towards organic compounds [38]. However, both cellulose and chitosan may serve as efficient sorbents of metals in stormwater because of their potential to attract cations [19, 39].

Due to the generally low removal of organic compounds using cellulose and chitosan, these materials were excluded from further testing. 


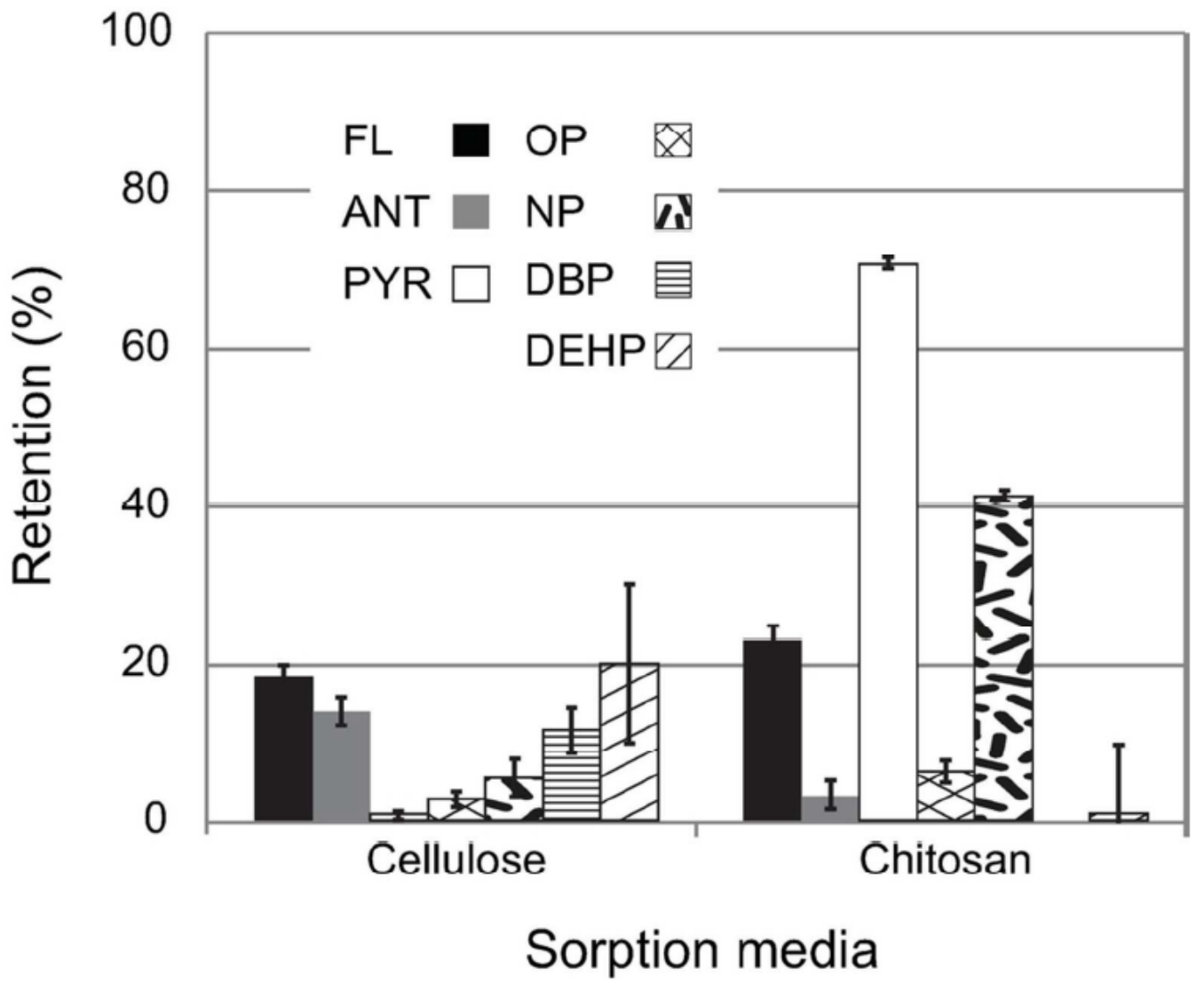

Figure 2. Retention (average of five tested concentrations) of fluorene (FL), anthracene $(A N T)$, pyrene $(P Y R)$, octylphenol $(O P)$, nonylphenol $(O P)$, dibutyl $(D B P)$ and di(2ethylhexyl) phthalate (DEHP) after 24 h contact with cellulose and chitosan. Error bars indicate standard error of retention.

PP/PE Fibres, Pine Bark and Chitosan-Covered Bark

In general, over $70 \%$ of the initial concentration of all tested compounds was removed using PP/PE fibres, with the exception of OP (46\%), and over $80 \%$ was removed using pine bark and chitosan-covered bark, with the exception of DEHP (50 and $<2 \%$, respectively). The water solubility of DEHP is very low (approximately $3 \times 10^{-3} \mathrm{mg} / \mathrm{L}$ [7]), and emulsion formation may occur during sample shaking. Hence inconsistent results are possible and the DEHP results should be interpreted with caution. The 
removed amount of organic compounds was either positively correlated with initial concentrations or constant over the spiked concentration range $(10-300 \mu \mathrm{g} / \mathrm{L})$. The PAHs were removed to the highest degree (92-97\%) by PP/PE fibres and both barks. The average removal of NP and DBP exceeded $80 \%$ using both barks, while the average removal of these compounds using $\mathrm{PP} / \mathrm{PE}$ was around $10 \%$ lower.

The PP/PE fibres and pine bark exhibited linear adsorption capacity for several of the compounds in the concentration range tested (Figure 3). It has been suggested that linear isotherms indicate that partitioning is taking place between the organic compound and organic sites on the adsorbent [40, 41]. Higher concentrations of the organic compounds (> $300 \mu \mathrm{g} / \mathrm{L}$ ) could not be tested due to their limited water solubility (1.3-19 mg/L for compounds except DEHP and PYR < $0.08 \mathrm{mg} / \mathrm{L}$ [7]). Pine bark and PP/PE fibres showed similar adsorption capacities for PAHs: approximately $1.4-44 \mu \mathrm{g} / \mathrm{g}$, the highest capacity corresponding to the highest spike level (Figure $3 \mathrm{a}-$ c). Pine bark demonstrated the highest adsorption capacities for alkylphenols (1.3-41 and $0.9-42 \mu \mathrm{g} / \mathrm{g}$ for OP and NP, respectively) and DBP $(1.1-41 \mu \mathrm{g} / \mathrm{g})$ (Figure $3 \mathrm{~d}-\mathrm{f}$ ). The PP/PE fibres adsorbed DEHP to the highest degree $(0.6-42 \mu \mathrm{g} / \mathrm{g})$, while its adsorption capacities for OP $(0.6-27 \mu \mathrm{g} / \mathrm{g}), \mathrm{NP}(1.1-37 \mu \mathrm{g} / \mathrm{g})$ and DBP $(0.9-37 \mu \mathrm{g} / \mathrm{g})$ were lower than for bark (Figure $3 \mathrm{~d}-\mathrm{g}$ ). However, no significant difference in adsorption capacity was found between the PP/PE fibres and pine bark (independent samples $t$-test, $p>.005$ for all spike levels), indicating that neither of these two materials was generally better able to adsorb all compounds tested. 
(a)

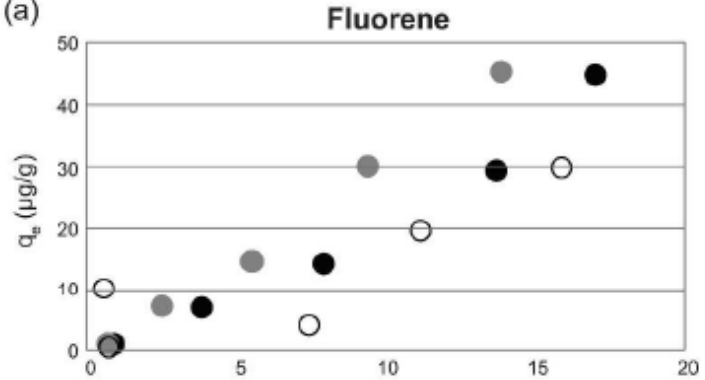

(b)

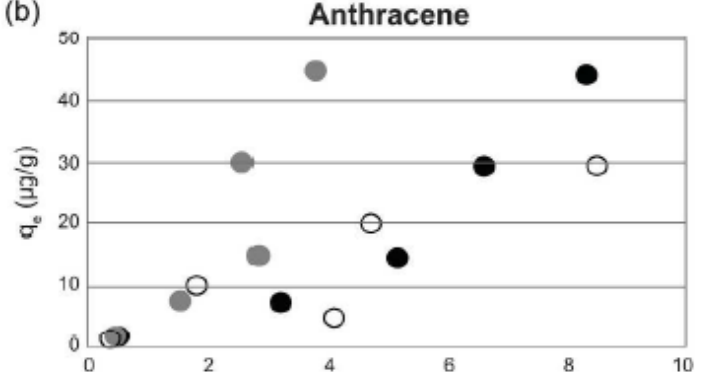

(c)

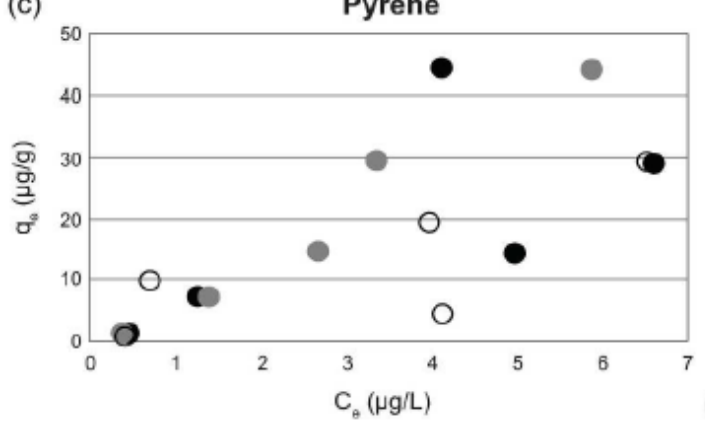

(d)

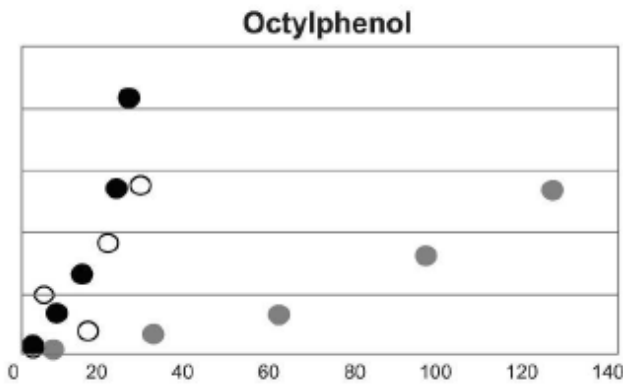

(e)

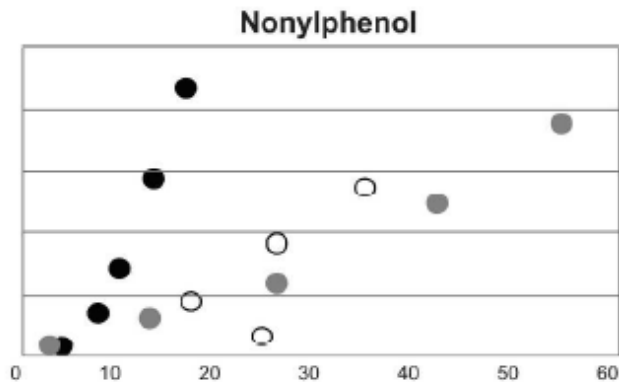

(f)

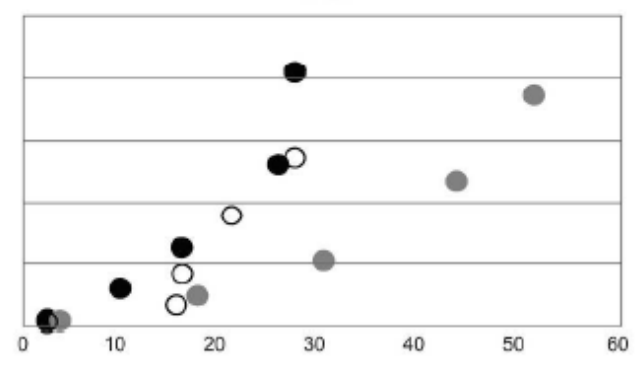

(g)

DEHP

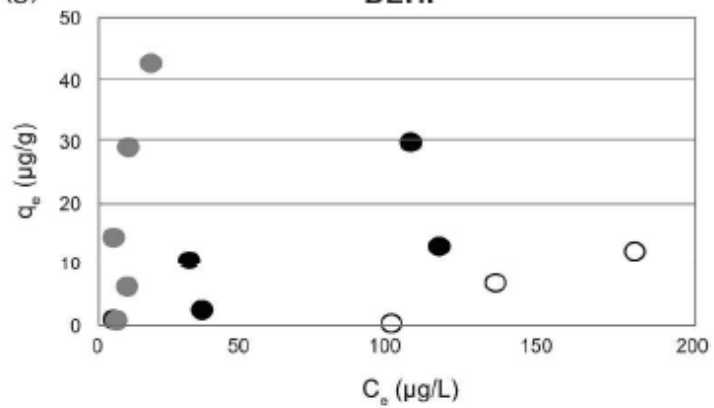

Figure 3. Adsorption capacity $\left(q_{e}\right)$ as a function of equilibrium concentration $\left(C_{e}, 24 \mathrm{~h}\right.$ adsorption) of (a) fluorene; (b) anthracene; (c) pyrene; (d) octylphenol; (e) nonylphenol; (f) DBP and; $(g)$ DEHP using pine bark, PP/PE fibres and chitosancovered pine bark.

Boving and Zhang [20] presented similar capacities for adsorption of FL, ANT and PYR onto aspen wood (up to $12 \mu \mathrm{g} / \mathrm{g}$, maximum initial concentration $50 \mu \mathrm{g} / \mathrm{L}$ ). Furthermore, adsorption capacities up to $70 \mu \mathrm{g} / \mathrm{g}$ for FL and benzyl butyl phthalate were 
reported by Ray et al. [21] using hardwood mulch (maximum initial concentration approximately $400 \mu \mathrm{g} / \mathrm{L}$ ). As a comparison, adsorption capacities in the $\mathrm{mg} / \mathrm{g}$-range have been reported for PAHs, phthalates and alkylphenols onto activated carbon [4244]. In previous studies, the adsorption capacities of three wood-based materials - a heat-treated pine bark; Zugol pine bark, which is the raw material for the chitosancovered bark used in the current study; and sawdust treated with polytetrafluoroethylene - were tested in adsorption batch studies [22]. The adsorption capacities of these three materials reached $38-45 \mu \mathrm{g} / \mathrm{g}$ for the same organic compounds at $C_{i}=300 \mu \mathrm{g} / \mathrm{L}$, i.e. very similar to the capacities of the pure pine bark tested in the current study.

The adsorption isotherms for chitosan-covered bark did not follow a linear tread, fluctuating more than for the pure pine bark (Figure $3 \mathrm{a}-\mathrm{g}$ ). Chitosan-covered bark was able to adsorb significantly lower masses of the organic compounds than pure pine bark (independent samples $t$-test, $p>.005$ for all spike levels). The adsorption capacity of chitosan-covered bark varied from $<1 \mu \mathrm{g} / \mathrm{g}$ at the lowest spike level (NP and DEHP were not adsorbed at $C_{i}=10 \mu \mathrm{g} / \mathrm{L}$ ) to $27-29 \mu \mathrm{g} / \mathrm{g}$ at the highest spike level (Figure $3 \mathrm{a}-$ g). The exception is DEHP which was not efficiently adsorbed at any tested concentration level $\left(q_{e} \leq 12 \mu \mathrm{g} / \mathrm{g}\right)$.

Chitosan exhibited low adsorption of the organic compounds (Figure 2) and chitosan-covered bark exhibited fluctuating adsorption isotherm results (Figure 3). It is assumed that the chitosan coverage of the bark plays a fundamental role in the adsorption capacity of the material. Chitosan is sprayed onto the bark, and uneven coverage is likely to occur. Consequently, bark particles covered with more or less chitosan will exhibit varying adsorption capacities. Chitosan-covered bark has the potential to adsorb both hydrophobic organic compounds, on the hydrophobic areas of the bark surface, and metals on the chitosan surface [19]. This material should be tested 
on a larger scale, i.e. not batch adsorption tests using small portions of the material, to avoid bias due to the varying degree of chitosan-coverage.

Based on the coefficients of determination for the linearized plots of model equations (Table 2), the Langmuir adsorption model was better than the Freundlich model to describe experimental data for most compounds' sorption onto PP/PE fibres and bark. For chitosan-covered bark, only DBP and PYR adsorption could be efficiently explained by the Langmuir model. However, most compounds exhibited negative $q_{\max }-$ values, indicating that the Langmuir model cannot adequately explain the adsorption process. In addition, adsorption of DEHP onto PP/PE fibres and FL, NP, ANT and DEHP onto chitosan-covered bark could not be predicted well by any of the isotherm models. 
Preprint. Accepted manuscript available online:

http://www.tandfonline.com/doi/full/10.1080/09593330.2017.1354924

Table 2. Coefficient of determination $\left(R^{2}\right)$ and Freundlich and Langmuir isotherm parameters for adsorption of organic compounds onto PP/PE fibres, pine bark and chitosan-covered bark.

\begin{tabular}{lccc|ccc|ccc}
\hline & \multicolumn{3}{c}{ PP/PE fibres } & \multicolumn{9}{c}{ Pine bark } \\
& & \multicolumn{1}{c}{ Freundlich model parameters } \\
& $R^{2}$ & $n^{a}$ & $K_{F}{ }^{a}$ & $R^{2}$ & $n$ & $K_{F}$ & $R^{2}$ & $n$ & $K_{F}$ \\
FL $^{\mathrm{b}}$ & 0.997 & 0.90 & 1.5 & 0.995 & 1.0 & 2.7 & 0.392 & 1.9 & 1.8 \\
OP & 0.980 & 0.79 & 0.27 & 0.984 & 1.0 & 2.8 & 0.648 & 1.1 & 0.95 \\
NP & 0.993 & 0.84 & 0.57 & 0.992 & 1.0 & 2.7 & 0.492 & 0.32 & $3.1 \cdot 10^{-2}$ \\
ANT & 0.987 & 0.78 & 2.0 & 0.851 & 1.2 & 3.2 & 0.542 & 1.2 & 1.9 \\
DBP & 0.971 & 0.72 & 0.4 & 0.983 & 1.0 & 2.8 & 0.872 & 0.70 & 0.45 \\
PYR & 0.935 & 0.66 & 2.0 & 0.947 & 1.1 & 2.9 & 0.802 & 1.0 & 1.6 \\
DEHP & 0.345 & 0.49 & 2.7 & 0.795 & 1.3 & 3.5 & 0.175 & 1.6 & 0.40 \\
\hline & & & & Langmuir model parameters & & & \\
& $R^{2}$ & $q_{\text {max }}{ }^{c}$ & $K_{L}{ }^{d}$ & $R^{2}$ & $q_{\text {max }}$ & $K_{L}$ & $R^{2}$ & $q_{\text {max }}$ & $K_{L}$ \\
FL & 0.997 & -45 & $-4.7 \cdot 10^{-2}$ & 1 & -75 & $-2.1 \cdot 10^{-2}$ & 0.191 & 4.7 & 1.0 \\
OP & 1 & -19 & $-4.6 \cdot 10^{-3}$ & 1 & -42 & $-1.9 \cdot 10^{-2}$ & 0.863 & -27 & $-2.1 \cdot 10^{-2}$ \\
NP & 1 & -37 & $-9.6 \cdot 10^{-3}$ & 0.929 & -2.0 & $-7.6 \cdot 10^{-2}$ & 0.016 & 5.3 & -0.13 \\
ANT & 0.998 & -24 & -0.15 & 0.969 & -24 & -0.13 & 0.714 & -30 & $-9.5 \cdot 10^{-2}$ \\
DBP & 0.999 & -18 & $-1.2 \cdot 10^{-2}$ & 0.999 & -14 & $-2.9 \cdot 10^{-3}$ & 0.984 & -15 & $-1.8 \cdot 10^{-2}$ \\
PYR & 0.997 & -15 & -0.21 & 0.994 & 2500 & $1.2 \cdot 10^{-3}$ & 0.964 & 120 & $2.5 \cdot 10^{-2}$ \\
DEHP & 0.162 & -3.7 & $-5.0 \cdot 10^{-2}$ & 0.943 & 46 & $3.1 \cdot 10^{-3}$ & 0.073 & 0.62 & $-9.0 \cdot 10^{-2}$ \\
\hline
\end{tabular}

${ }^{\mathrm{a}} K_{\mathrm{F}}\left((\mu \mathrm{g} / \mathrm{g})(\mathrm{L} / \mu \mathrm{g})^{1 / \mathrm{n}}\right)$ and $n$ are Freundlich model constants.

${ }^{\mathrm{b}} \mathrm{FL}$ - fluorene, ANT - anthracene, PYR - pyrene, OP - 4-t-octylphenol, NP - 4-nonylphenol, DBP - dibutyl phthalate, DEHP - di(2-ethylhexyl) phthalate.

${ }^{\mathrm{c}} q_{\max }(\mu \mathrm{g} / \mathrm{g})$ is the maximum adsorption capacity.

${ }^{\mathrm{d}} K_{L}(\mathrm{~L} / \mu \mathrm{g})$ is the Langmuir constant.

The Langmuir model assumes monolayer molecular adsorption and is said to better describe chemisorption, while the Freundlich model describes equilibrium on heterogeneous surfaces where monolayer and multilayer adsorption may occur $[45,46]$.

Chemisorption implies covalent, ionic and metallic bonds that are highly specific, whereas physisorption is attributed mainly to van der Waals forces. However, because 
of the negative $q_{\max }$-values for the Langmuir model (Table 2), the Langmuir isotherm is not appropriate and physisorption should not be ruled out.

Polypropylene and polyethylene are non-polar polymers; adsorption of nonpolar PAHs is therefore likely to be higher than for alkylphenol and phthalates (Figure 3), which have both hydrophobic hydrocarbon chains and hydrophilic hydroxyl and ester groups, respectively. Wood consists of three major components - cellulose, hemicellulose and lignin - with significantly different surface chemistry, hence affinity to sorb organic compounds $[47,48]$. Lignin provides many hydrophobic sites which may attract hydrophobic compounds. On the other hand, cellulose and hemicellulose contain hydroxyl and carboxylic groups which are not favourable for attracting hydrophobic compounds. In addition, these groups can produce strong hydrogen bonds with water, inhibiting sorption of PAHs [49]. Hence, it is concluded that the hydrophobic organic compounds tested in the current study are mainly attracted to the lignin part of the wood structure, and that cellulose is not involved in the sorption of these compounds. The limited adsorption onto cellulose was shown in Figure 2, as well as in other studies $[41,47]$. The sorption capacity of wood-based media could be improved by modifying the material through extraction of inhibiting moieties such as cellulose [50], although this would involve higher material costs.

Only slight differences in adsorption capacities were observed between PAHs and other tested compounds on pine bark. However, the higher adsorption of PAH compared to alkylphenols and phthalates may be due to the higher number of aromatic rings in the PAH molecules $(2-4$ rings in the PAHs' structure; 1 ring in OP, NP, DBP and DEHP), leading to increased strength of $\pi-\pi$ interactions $[47,50]$.

A generally high removal of organic compounds with PP/PE fibres, pure pinebark and chitosan-covered bark was observed (70-97\%), with a few exceptions (DEHP 
using both barks and OP using PP/PE). This indicates that, despite possible colloidformation, humic acids did not have a substantial negative effect on the adsorption of organic pollutants in this study. This is true even for the wood-based materials, which are not expected to adsorb humic colloids and thereto attached contaminants [10, 39]. Hence it is assumed that the organic compounds do not form HA-complexes to a high degree in these experiments. Low formation of HA-organic compounds complexes may be due to short contact time $(\leq 24 \mathrm{~h})$ between organic compounds and HAs [51], and abundance of hydrophobic sites on the wood-based materials and PP/PE, so that compound sorption to adsorbents is favoured.

\section{Kinetics}

Adsorption is a time-dependent process, so it is necessary to evaluate an optimal contact time between the organic compounds and the adsorbents for design and use, e.g. in filters. Cellulose and chitosan were not included in the kinetic tests due to their low adsorption capacities. In addition, chitosan-covered bark exhibited fluctuating results for the adsorption isotherms, and hence was not included in the kinetic tests.

The adsorption of organic compounds occurred within $10 \mathrm{~min}$ in contact with PP/PE fibres (Figure 4 a). For pine bark, maximum sorption was not attained after 120 min, but the differences in adsorption capacity at $30 \mathrm{~min}$ (Figure $4 \mathrm{~b}$ ) and $24 \mathrm{~h}$ (Figure 3 a-g) were generally only around $10 \%$. A similar adsorption equilibrium process has been reported for other plant-based media, such as metals on mulch [52] and sawdust [28], and bisphenol A onto natural sorbents such as rice husk, sawdust and peat [53]. In addition, in previous studies of wood-based materials [22], the bulk adsorption of organic compounds occurred within 10 min contact with material. 

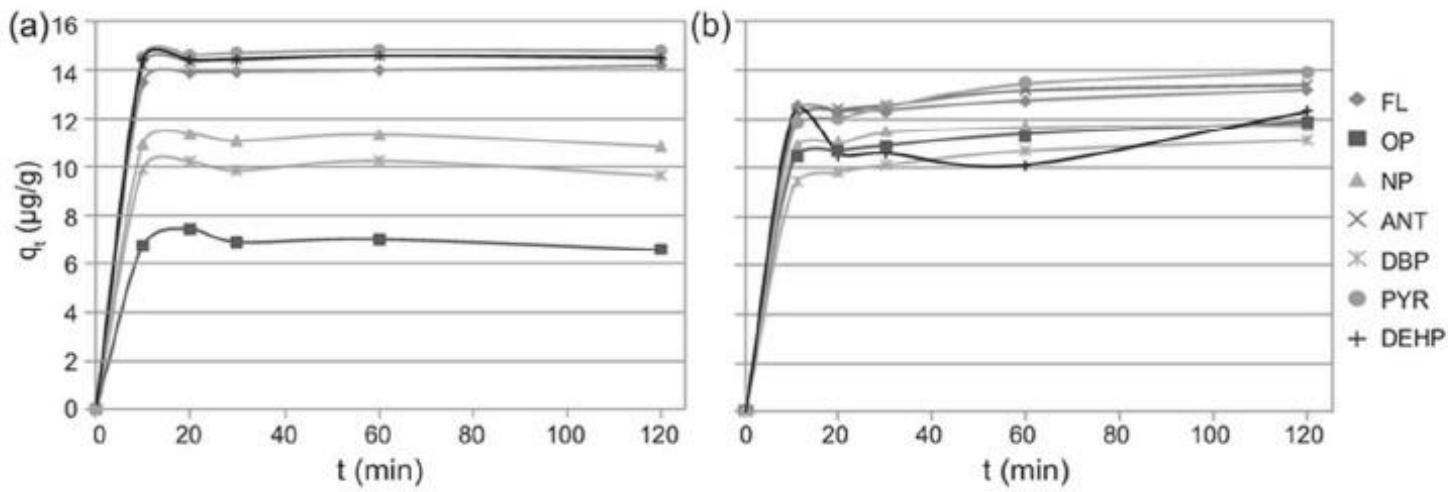

Figure 4. Adsorption capacities $\left(q_{t}\right)$ of (a) PP/PE fibres and $(b)$ pine bark as functions of time $(t)$.

Similar to results presented by such authors as Bulut and Tez [28] and Jang et al. [52] for metal adsorption onto sawdust and mulch, respectively, plotting the first-order kinetic model for pine bark indicates that this equation is only valid for certain compounds during the initial 0-30 min of the adsorption process. Even weaker agreement with the first-order equation was found for PP/PE fibres (Table 3). However, for the second-order kinetic model, $\mathrm{R}^{2} \geq 0.99$ for all compounds sorbing to $\mathrm{PP} / \mathrm{PE}$ fibres and pine bark (Table 3), indicating that the pseudo-second-order model fits the adsorption process well in this study. The experimental and calculated $q_{e^{-}}$values for all compounds are in good agreement (Table 3), further supporting the pseudo-secondorder model for the adsorption kinetics in this study. The rate constants for PP/PE fibres $(M=0.41, S D=0.53)$ are not significantly higher than for pine bark $(M=0.05, S D=$ $0.04), t(14)=1.93, p=.095$.

Table 3. Coefficient of determination $\left(R^{2}\right)$ for kinetic first- and second-order linear model plots, and second-order model parameters for adsorption on PP/PE fibres and pine bark. 


\begin{tabular}{|c|c|c|c|c|c|}
\hline & First order & \multicolumn{4}{|c|}{ Second order } \\
\hline & \multicolumn{5}{|c|}{ PP/PE fibres } \\
\hline & $R^{2}$ & $R^{2}$ & $k_{2}^{a}$ & $q_{e}, \operatorname{calc}^{b}$ & $q_{e}, \exp ^{c}$ \\
\hline $\mathrm{FL}^{\mathrm{d}}$ & 0.178 & 1.000 & 0.106 & 14.25 & 14.18 \\
\hline ANT & 0.450 & 1.000 & 0.230 & 14.62 & 14.60 \\
\hline PYR & $\mathrm{n} / \mathrm{a}^{\mathrm{e}}$ & 1.000 & 0.308 & 14.81 & 14.58 \\
\hline $\mathrm{OP}$ & $\mathrm{n} / \mathrm{a}$ & 0.999 & 0.083 & 6.56 & 6.15 \\
\hline NP & 0.016 & 0.999 & 0.102 & 10.82 & 11.11 \\
\hline DBP & 0.131 & 0.999 & 0.088 & 9.62 & 10.44 \\
\hline \multirow[t]{2}{*}{ DEHP } & $\mathrm{n} / \mathrm{a}$ & 1.000 & 1.582 & 14.51 & 14.24 \\
\hline & \multicolumn{5}{|c|}{ Pine bark } \\
\hline FL & 0.996 & 1.000 & 0.042 & 13.33 & 13.82 \\
\hline ANT & 0.886 & 1.000 & 0.037 & 13.61 & 14.26 \\
\hline PYR & 0.988 & 1.000 & 0.020 & 14.31 & 14.23 \\
\hline $\mathrm{OP}$ & 0.969 & 1.000 & 0.030 & 12.12 & 13.04 \\
\hline NP & 0.700 & 1.000 & 0.064 & 11.89 & 13.50 \\
\hline DBP & 0.918 & 1.000 & 0.027 & 11.39 & 12.58 \\
\hline DEHP & 0.023 & 0.986 & 0.018 & 12.36 & 10.42 \\
\hline
\end{tabular}

${ }^{\mathrm{a}} k_{2}(\mathrm{~g} /(\mu \mathrm{g} \mathrm{min}))$ is the pseudo-second-order rate constant of adsorption.

${ }^{\mathrm{b}} q_{e}$ calc $(\mu \mathrm{g} / \mathrm{g})$ is the calculated adsorption capacity at $t=24 \mathrm{~h}$ (assumed equilibrium).

${ }^{\mathrm{c}} q_{e}, \exp (\mu \mathrm{g} / \mathrm{g})$ is the experimentally determined $q_{e}$ at $t=24 \mathrm{~h}$.

${ }^{\mathrm{d}} \mathrm{FL}$ - fluorene, ANT - anthracene, PYR - pyrene, OP - 4-t-octylphenol, NP - 4-nonylphenol, DBP - dibutyl phthalate, DEHP - di(2-ethylhexyl) phthalate.

${ }^{\mathrm{e}}$ not applicable, due to $q_{e}=q_{t}$ for some time points, its log could not be calculated and plotted.

\section{Conclusions}

The capacity of cellulose to adsorb organic compounds was negligible and chitosan adsorbed only the most hydrophobic compounds tested. In general, the batch adsorption tests indicate that pine bark and fibres of PP/PE have potential for use in filters for removal or hydrophobic organic compounds frequently detected in stormwater. These materials are inexpensive and abundant, show adequate sorption capacity (up to 44 $\mu \mathrm{g} / \mathrm{g}$ ) and exhibit relatively fast removal (> 70\% within $30 \mathrm{~min}$ ) for the organic pollutants tested. Results from the current study and from a previous study of two 
different types of pine bark [22], indicate that barks with different pre-treatment (none, heat) or provided by different manufacturers exhibit little or no difference in adsorption capacity for hydrophobic organic compounds.

Further research should investigate whether the filter materials are effective in removing pollutants from natural stormwater, where many influencing factors, such as fluctuating pollutant concentrations, water flows, contact time, particle content and colloidal transport, can affect the adsorption capacity of the materials. For practical reasons, contact times less than 10 minutes were not tested in the current study. However, in operating stormwater filters, contact times can be expected to be shorter than 10 minutes. Currently, a filter pilot plant using three different filter materials, of which the tested pine bark is one, is in operation. The objective is to investigate the efficiency of selected sorption filters for the removal of dissolved and colloidal organic pollutants from road runoff, and to estimate the life-time of the materials before saturation occurs. Results from this pilot study will be published in the future. 


\section{References}

1. Björklund K, Palm Cousins A, Strömvall AM, Malmqvist, PA. Phthalates and nonylphenols in urban runoff: Occurrence, distribution and area emission factors. Sci Total Environ. 2009;407:4665-4672.

2. Björklund K, Strömvall AM, Malmqvist PA. Screening of Organic Contaminants in Urban Snow. Water Sci Technol. 2011;64:206-13.

3. Zgheib S, Moilleron R, Saad M, Chebbo G. Partition of pollution between dissolved and particulate phases: what about emerging substances in urban stormwater catchments? Water Res. 2011;45:913-925.

4. Clara M, Windhofer G, Hartl W, Braun K, Simon M, Gans O, Scheffknecht C, Chovanec A. Occurrence of phthalates in surface runoff, untreated and treated wastewater and fate during wastewater treatment. Chemosphere. 2010;78:10781084.

5. Eriksson E, Baun A, Mikkelsen PS, Ledin A. Risk assessment of xenobiotics in stormwater discharged to Harrestrup A, Denmark. Desalination. 2007;215:187197.

6. Staples CA, Peterson DR, Parkerton TF, Adams WJ. The environmental fate of phthalate esters: A literature review. Chemosphere. 1997;35:667-749.

7. Mackay D, Shiu WY, Ma KC, Lee SC. Handbook of Physical-Chemical Properties and Environmental Fate for Organic Chemicals. 2nd ed. Boca Raton (FL), USA: CRC Press, Taylor \& Francis Group; 2006.

8. Ahel M, Giger W. Partitioning of alkylphenols and alkylphenol polyethoxylates between water and organic solvents. Chemosphere. 1993;26:1471-1478.

9. Kalmykova Y, Björklund K, Strömvall AM, Blom L. Partitioning of polycyclic aromatic hydrocarbons, alkylphenols, bisphenol A and phthalates in landfill leachates and stormwater. Water Res. 2013;47:1317-1328.

10. Kalmykova Y, Moona N, Strömvall AM, Björklund K. Sorption and Degradation of Petroleum Hydrocarbons, Polycyclic Aromatic Hydrocarbons, Alkylphenols, Bisphenol A and Phthalates in Landfill Leachate Using Sand, Activated Carbon and Peat Filters. Water Res. 2014;56:246-257.

11. Durjava MK, ter Laak TL, Hermens JLM, Struijs J. Distribution of PAHs and PCBs to dissolved organic matter: High distribution coefficients with consequences for environmental fate modeling. Chemosphere. 2007;67:990-997. 
12. McPhedran KN, Seth R, Drouillard KG. Hydrophobic organic compound (HOC) partitioning behaviour to municipal wastewater colloidal organic carbon. Water Res. 2013;47:2222-2230.

13. Genç-Fuhrman H, Mikkelsen PS, Ledin A. Simultaneous removal of As, Cd, Cr, $\mathrm{Cu}, \mathrm{Ni}$ and $\mathrm{Zn}$ from stormwater: Experimental comparison of 11 different sorbents. Water Res. 2007;41:591-602.

14. Al-Anbari R, Wootton K, Durmanic S, Deletic A, Fletcher T. Evaluation of media for the adsorption of stormwater pollutants. Proceedings of the 11th International Conference on Urban Drainage; 2008 August 31-September 5; Edinburgh, UK.

15. Seelsaen N, McLaughlan R, Moore S, Ball JE, Stuetz RM. Pollutant removal efficiency of alternative filtration media in stormwater treatment. Water Sci Technol. 2006;54:299-305.

16. Färm C. Metal sorption to natural filter substrates for storm water treatmentcolumn studies. Sci Total Environ. 2002;298:17-24.

17. Pitcher SK, Slade RCT, Ward NI. Heavy metal removal from motorway stormwater using zeolites. Sci Total Environ. 2004;334-335:161-166.

18. Nehrenheim E, Gustafsson JP. Kinetic sorption modelling of $\mathrm{Cu}, \mathrm{Ni}, \mathrm{Zn}, \mathrm{Pb}$ and Cr ions to pine bark and blast furnace slag by using batch experiments. Bioresource Technol. 2008;99:1571-1577.

19. Babel S, Kurniawan TA. Low-cost adsorbents for heavy metals uptake from contaminated water: a review. J Hazard Mater, 2003;97:219-243.

20. Boving TB, Neary K. Attenuation of polycyclic aromatic hydrocarbons from urban stormwater runoff by wood filters. J Contam Hydro: 2007;91:43-57.

21. Ray AB, Selvakumar A, Tafuri AN. Removal of selected pollutants from aqueous media by hardwood mulch. J Hazard Mater. 2006;136:213-218.

22. Björklund K, Li L. Evaluation of low-cost materials for sorption of hydrophobic organic pollutants in stormwater. J Environ Manage. 2015;159:106-114.

23. Suhas, Gupta VK, Carrott PJM, Singh R, Chaudhary M, Kushwaha S. Cellulose: A review as natural, modified and activated carbon adsorbent. Bioresource Technol. 2016;216:1066-1076. 
24. Sheldrick BH. Analytical Methods Manual. Land Resource Research Institute, Research Branch, Agriculture Canada: Ottawa, Canada. Report number: LRRI Contribution No. 84-30; 1984.

25. Brown JN, Peake BM. Determination of colloidally-associated polycyclic aromatic hydrocarbons (PAHs) in fresh water using $\mathrm{C} 18$ solid phase extraction disks. Anal Chim Acta. 2003;486:159-169.

26. Kalmykova Y, Rauch S, Strömvall AM, Morrison G, Stolpe B, Hassellöv M. Colloid-Facilitated Metal Transport in Peat Filters. Water Environ Res. 2010;82:506-511.

27. National Stormwater Quality Database (NSQD, version 1.1) [Internet]. Tuscaloosa (AL), USA: University of Alabama; 2004 [cited 2016 April 30]. Available from: http://rpitt.eng.ua.edu/Research/ms4/Paper/Mainms4paper.html.

28. Bulut Y, Tez Z. Removal of heavy metals from aqueous solution by sawdust adsorption. J Environ Sci. 2007;19:160-166.

29. Gök Ö, Özcan AS, Özcan A. Adsorption kinetics of naphthalene onto organosepiolite from aqueous solutions. Desalination. 2008;220:96-107.

30. Vakili M, Rafatullah M, Salamatinia B, Abdullah AZ, Ibrahim MH, Tan KB, Gholami Z, Amouzgar P. Application of chitosan and its derivatives as adsorbents for dye removal from water and wastewater: A review. Carbohyd Polym. 2014;113:115-130.

31. Ioannidou O, Zabaniotou A. Agricultural residues as precursors for activated carbon production-A review. Renew Sustainable Energy Rev. 2007;11:19662005.

32. Shin HS, Monsallier JM, Choppin GR. Spectroscopic and chemical characterizations of molecular size fractionated humic acid. Talanta. 1999;50:641-647.

33. Zhang X, Bai R. Mechanisms and kinetics of humic acid adsorption onto chitosan-coated granules. J Colloid Interface Sci. 2003;264:30-38.

34. Ngah WSW, Musa A. Adsorption of humic acid onto chitin and chitosan. J Appl Polym Sci. 1998;69:2305-2310.

35. Wan Ngah WS, Hanafiah MAKM. Removal of heavy metal ions from wastewater by chemically modified plant wastes as adsorbents: A review. Bioresource Technol. 2008;99:3935-3948. 
36. Crisafully R, Milhome MAL, Cavalcante RM, Silveira ER, De Keukeleire D, Nascimento RF. Removal of some polycyclic aromatic hydrocarbons from petrochemical wastewater using low-cost adsorbents of natural origin. Bioresource Technol. 2008;99:4515-4519.

37. Lang W, Dejma C, Sirisansaneeyakul S, Sakairi N. Biosorption of nonylphenol on dead biomass of Rhizopus arrhizus encapsulated in chitosan beads.

Bioresource Technol. 2009;100:5616-5623.

38. Hokkanen S, Bhatnagar A, Sillanpää M. A review on modification methods to cellulose-based adsorbents to improve adsorption capacity. Water Res. 2016;91:156-173.

39. Rowell RM, Pettersen R, Tshabalala MA. Cell Wall Chemistry. In: Rowell RM, editor. Handbook of Wood Chemistry and Wood Composites. 2nd ed. Boca Raton (FL), USA: CRC Press; 2012. p. 33-72.

40. Brás I, Lemos L, Alves A, Pereira MFR. Sorption of pentachlorophenol on pine bark. Chemosphere. 2005;60:1095-1102.

41. Jonker MTO. Absorption of polycyclic aromatic hydrocarbons to cellulose. Chemosphere. 2008;70:778-782.

42. Julinová M, Slavík R. Removal of phthalates from aqueous solution by different adsorbents: A short review. J Environ Manage. 2012;94:13-24.

43. Liu J, Chen J, Jiang L, Yin X. Adsorption of mixed polycyclic aromatic hydrocarbons in surfactant solutions by activated carbon. J Ind Eng Chem. 2014;20:616-623.

44. Yu Z, Peldszus S, Huck PM. Adsorption characteristics of selected pharmaceuticals and an endocrine disrupting compound-Naproxen, carbamazepine and nonylphenol—on activated carbon. Water Res. 2008;42:2873-2882.

45. Boparai HK, Joseph M, O'Carroll DM. Kinetics and thermodynamics of cadmium ion removal by adsorption onto nano zerovalent iron particles. J Hazard Mater. 2011;186:458-465.

46. Ruthven DM. Fundamentals of Adsorption Equilibrium and Kinetics in Microporous Solids. In: Karge H and Weitkamp J, editors. Adsorption and Diffusion. Berlin Heidelberg, Germany: Springer; 2008. p. 1-43. 
47. Huang L, Boving TB, Xing B. Sorption of PAHs by Aspen Wood Fibers as Affected by Chemical Alterations. Environ Sci Technol. 2006;40:3279-3284.

48. MacKay AA, Gschwend PM. Sorption of Monoaromatic Hydrocarbons to Wood. Environ Sci Technol. 2000;34:839-45.

49. Chen B, Schnoor JL. Role of Suberin, Suberan, and Hemicellulose in Phenanthrene Sorption by Root Tissue Fractions of Switchgrass (Panicum virgatum) Seedlings. Environ Sci Technol. 2009;43:4130-4136.

50. Li Y, Chen B, Zhu L. Enhanced sorption of polycyclic aromatic hydrocarbons from aqueous solution by modified pine bark. Bioresource Technol. 2010;101:7307-7313.

51. Kreeke Jvd, Calle Bdl, Held A, Bercaru O, Ricci M, Shegunova P, Taylor P. IMEP-23: The eight EU-WFD priority PAHs in water in the presence of humic acid. Trend Anal Chem. 2010;29:928-937.

52. Jang A, Seo Y, Bishop PL. The removal of heavy metals in urban runoff by sorption on mulch. Environ Pollut. 2005;133:117-127.

53. Zhou Y, Lu P, Lu J. Application of natural biosorbent and modified peat for bisphenol a removal from aqueous solutions. Carbohyd Polym. 2012;88:502508. 